ISSN (e)-2347-176x ISSN (p) 2455-0450

crossrefDOI: https://dx.doi.org/10.18535/jmscr/v7i1.90

\title{
Placenta Previa: Maternal and Foetal Outcome in a Tertiary Care Hospital of Telangana State
}

\author{
Authors \\ Dr Jalagam Madhavi ${ }^{1}$ and Dr V. Usha Rani ${ }^{2 *}$ \\ ${ }^{1}$ Assistant Professor, Dept. of Obstetrics \& Gynaecology, Kakatiya medical college, Warangal, Telangana \\ State, Email: drmadhavikishore@gmail.com, Mobile: 9866223261 \\ ${ }^{2}$ Associate Professor, Dept. of Obstetrics \& Gynaecology, Kakatiya medical college, Warangal, Telangana \\ State \\ Corresponding Author \\ Dr. V. Usha Rani
}

Associate Professor, Dept. of Obstetrics \& Gynaecology, Kakatiya medical college, Warangal,

Telangana State, India

\begin{abstract}
Placenta previa is an increasingly prevalent and potentially dangerous complication of pregnancy. This study was conducted at Goverment maternity Hospital, Hanamkonda, Telangana state. The no of deliveries conducted during this study period was 7626. In this 322(4.22\%) were admitted with APH. In those $68(0.89 \%)$ patients were of placenta previa. This study includes 60cases. Mean age was $28.96 \pm 10.42$ years. Placenta previa was more common 25-35 years age group (77\%). About $70 \%$ multiparous women had placenta previa compared to $30 \%$ primiparous women. The most common gestational age which presented with bleeding was 34-38 week. Twin gestation and previous caesarean sections were of risk factors. Malpresentations was also noticed in $8.8 \%$ cases. In our study, $31.6 \%$ patients had a history of prior caesarean section. Grading of placenta previa as major (complete and partial) in 63\% patients and minor (marginal and low lying) in 37\% of people. Bleeding was found in almost all cases these patients were monitored closely as inpatients and more aggressively managed. In 68\% of people emergency surgery was done and $16 \%$ cases elective surgery were conducted. Severe Anaemia was noticed in $40 \%$ cases, blood transfusion was done in $50 \%$ of cases in which $20 \%$ were antenatal blood transfusion. The post operative complications like Sepsis (6.6\%), Febrile morbidity(6.6\%), UTI(6.6\%) and PPH(13.3\%) were recorded. About $25 \%$ of neonates require resuscitation, $20 \%$ were admitted in NICU, 4 were died after 48 hours. As the maternal and perinatal morbidity and mortality due to placenta previa is preventable, efforts should be made to bring down these rates at tertiary care hospitals.
\end{abstract}

Keywords: placenta previa, maternal outcome, neonatal outcome, haemorrhage, blood transfusion.

\section{Introduction}

Antepartum haemorrhage forms one of the most dangerous and devastating group of disorders in obstetrics. Placenta previa contributes to one of the cases of antepartum haemorrhage. Placenta previa involves bleeding from placental site completely, which is located in the lower uterine segment either partially or completely and as the lower uterine segment stretches near term or in labour the associated bleeding is inevitable. Maternal and fetal morbidity and mortality from PP are considerable, 
and associated with high demands on health care resources $^{[1,2]}$.

It occurs in 2.8/1000 singleton pregnancies and $3.9 / 1000$ twin pregnancies. The incidence of hysterectomy after caesarean section (CS) for placenta previa is $5.3 \%$ (relative risk compared with those undergoing CS without placenta previa in 33) ${ }^{[3]}$. Perinatal mortality rates are three or four times higher than in normal pregnancies ${ }^{[4]}$

$\mathrm{PP}$ is known to be associated with prematurity ${ }^{[5]}$ However, there is debate about the effect of PP on fetal growth; some studies have suggested that pregnancies with PP are at risk of low birth weight and a low Apgar score.

Painless bleeding is the most characteristics event with placenta previa. Bleeding from a previa usually begins without warning and without pain or contractions in a woman who has had an uneventful prenatal course. Usually it ceases, only to recur.

The majority of cases of placenta previa are diagnosed during routine sonography, a transvaginal approach is adequate in revealing the position. Women who present with bleeding in the second half of pregnancy should have a sonographic examination for placental location prior to any attempt to perform a digital examination. Management includes constant observation and monitoring, administration of intravenous fluids, transfusion therapy, assessment of renal function and intravascular status, assessment of the fetus, and delivery. ${ }^{[6]}$

Women in whom the distance between the lower placental edge and the internal cervical os was greater than $2 \mathrm{~cm}$ could safely have a vaginal delivery. In women with a placenta-internal os distance less than $2 \mathrm{~cm}$, majority required cesarean delivery, usually for bleeding. Studies suggest that women with placenta previa should have a transvaginal sonogram in the late third trimester, and those with a placental edge to internal os distance of less than $2 \mathrm{~cm}$ should be delivered by cesarean. Women whose placentas are $2 \mathrm{~cm}$ or more from the os undergo a normal labour. ${ }^{[7]}$

The aim of the present study was to evaluate maternal and neonatal outcomes in cases of Placenta
Previa in government maternity hospital, Hanamkonda, Telangana state.

\section{Material and Methods}

This study was conducted in the Department of Obstetrics and Gynaecology during the period from January 2017 to December 2017.All antenatal patients of 24 weeks of gestation regardless of their parity. Patients who have diagnosed to have low lying placenta in their mid-trimester scanning will be taken in this study.

Data were collected on patient age, parity, gestational age at time of cesarean section, history of previous cesarean section (s), and degree of PP by ultrasound. The evaluation also included whether cesarean section was done electively or as an emergency, operative time, estimated blood loss during surgery, and units of packed red blood cell (PRBC) transfusion given.

Statistical analysis was done using SPSS version 16.0 for Windows. Data was expressed as frequencies and percentages.

\section{Results}

In the present study, analysis of maternal and neonatal outcomes in cases of placenta previa occurring over a period of one year from January 2017 to December 2017 studied at the Government maternity Hospital, Warangal, Telangana state. The no of deliveries conducted during this study period was 7626. In this 322(4.22\%) were admitted with APH. In those $68(0.89 \%)$ patients were of placenta previa. Eight patients were not included in this study due to different reasons. This includes 60 cases of placenta previa. The parameter like age of patients, gestational age, parity and mode of delivery were shown in table 1.

Table 1: Patients details - age, gestational age, parity and mode of delivery

\begin{tabular}{|l|c|}
\hline Parameter & No of patients \\
\hline Age (years) (mean \pm SD) & $28.96 \pm 10.42$ \\
\hline$>25$ & $10(16 \%)$ \\
\hline $25-35$ & $46(77 \%)$ \\
\hline$>35$ & $4(6.6 \%)$ \\
\hline Gestational age (weeks) & \\
\hline $24-30$ & $2(3.3 \%)$ \\
\hline $31-36$ & $19(31.6 \%)$ \\
\hline
\end{tabular}




\begin{tabular}{|l|c|}
\hline$>36$ & $39(65 \%)$ \\
\hline Parity (mean \pm SD) & \\
\hline primi & $18(30 \%)$ \\
\hline Multi & $42(70 \%)$ \\
\hline Twin gestation & $2(3.3 \%)$ \\
\hline Previous caesarean section & $19(31.6 \%)$ \\
\hline Grade of PP & $38(63 \%)$ \\
\hline Major (complete and partial) $(\mathrm{n}, \%)$ & $22(37 \%)$ \\
\hline Minor (marginal and low lying) $(\mathrm{n}, \%)$ & $41(68 \%)$ \\
\hline Emergency surgery (n, \%) & $10(16.6 \%)$ \\
\hline Elective surgery (n, \%) & $>5$ days \\
\hline Hospital stay & \\
\hline
\end{tabular}

Table 2: Antenatal complications

\begin{tabular}{|l|c|}
\hline Parameter & No of patients \\
\hline No. of episodes of bleeding & $30-50$ \\
\hline Severe anaemia $(<7 \mathrm{~g} \%)$ & $24(40 \%)$ \\
\hline Patients in shock & $4(6.6 \%)$ \\
\hline blood transfusions & $30(50 \%)$ \\
\hline Malpresentation-breech & $5(8.3 \%)$ \\
\hline IUD & $6(10 \%)$ \\
\hline
\end{tabular}

Table 3: Intra -operative complications

\begin{tabular}{|l|c|}
\hline Parameter & No of patients \\
\hline Haemostatic sutures Cho's & $1(1.6 \%)$ \\
\hline Vertical haemostatic sutures B-lynch & $1(1.6 \%)$ \\
\hline
\end{tabular}

Table 4: post operative complications

\begin{tabular}{|l|c|}
\hline Parameter & No of patients \\
\hline Sepsis & $4(6.6 \%)$ \\
\hline Febrile morbidity & $6(10 \%)$ \\
\hline UTI & $4(6.6 \%)$ \\
\hline PPH & $8(13.3 \%)$ \\
\hline Nil & $38(63.3 \%)$ \\
\hline
\end{tabular}

Table 5: Neonatal outcome

\begin{tabular}{|l|c|}
\hline Parameter & No of patients \\
\hline $\begin{array}{l}\text { No. of neonates requiring no } \\
\text { resuscitation }\end{array}$ & $15(25 \%)$ \\
\hline NICU admissions & $12(20 \%)$ \\
\hline Expired within 48 hours & $4(6.6 \%)$ \\
\hline
\end{tabular}

\section{Discussion}

In placenta previa (PP), the placenta is located over or very near the internal cervical os. Maternal and fetal morbidity and mortality from PP are considerable, and associated with high demands on health care resources. Given the rising incidence of cesarean section combined with increasing maternal age, the number of cases of PP and its complications. In the present study 60 cases of placenta previa were studied regarding the type of clinical presentation, the clinical course, the perinatal and maternal outcome. In this study incidence of APH was $4.22 \%$ and among those $0.89 \%$ was placenta previa, almost similar to study conducted by other authors $^{[8,9]}$. In the present study $70 \%$ multiparous women had placenta previa compared to $30 \%$ primiparous women. These studies correlate with the statistic of studies done by others ${ }^{[10,11]}$ The incidence of twin gestation in the present study was $3.3 \%$, twin gestations was also reported by others was one of risk factor for placenta previa ${ }^{[12]}$. Majority of patients are in the age group 25-35[70\%] and the most common gestational age in our study group, which presented with bleeding was 34-38 weeks, similar findings in Tariq et al study showed maximum number of patients with first episodes of bleeding in 34-38 weeks group followed by 30-34 weeks ${ }^{[11]}$. Malpresentations in our study is almost similar to the study conducted by others ${ }^{[13]}$

In our study, $31.6 \%$ patients had a history of prior caesarean section. Our study showed that the risk of placenta previa was more among patients with a previous history of caesarean section, This incidence increased as the number of previous caesarean sections increased.

Grading of placenta previa as Major (complete and partial) in $63 \%$ patients and Minor (marginal and low lying) $37 \%$ of people. In our study, second trimester bleeding was found in $31.6 \%$ cases and third trimester bleeding was found in $65 \%$ cases these patients were monitored closely as inpatients and more aggressively managed.

In our study, $70 \%$ cases of placenta previa was delivered by caesarean section. Elective CS at 37 weeks, $68 \%$ of cases were emergency LSCS due to recurrent bleeding. Lesser degrees of previa had vaginal delivery and had to be helped out by vacuum extraction. In other studies also less degrees of previa had vaginal deliveries ${ }^{[14]}$.

Antepartum haemorrhage occurred in $70 \%$ of placenta previa cases in our study. Blood transfusion was given for $50 \%$ of patients with previa. Of these $20 \%$ was antepartum and $30 \%$ was in the intrapartum and postpartum period. In Crane $\mathrm{JM}$ et $\mathrm{al}^{[15]} \mathrm{A}$ relative risk of 9.72 for antepartum transfusion and RR of 7.25 for intra / post-partum 
transfusion was seen this was in comparison with our study.

In our study post operative complications like sepsis, febrile illness, UTI and shock When compared with the study done by McShane. This indicates that we must acquire a more appropriate and prompt approach in the management of placenta previa with good antibiotic coverage and better aseptic precaution. Resuscitation required for the neonates in the present study was $25 \%$, whereas in the study done by McShane it was 33\%. NICU admissions in the present study done by McShane were $20 \%$ and $10 \%$ respectively, again indicating the inadequacy in our antenatal and perinatal care ${ }^{[16]}$.

Perinatal mortality is $6.6 \%$ in our study in all birth weight groups when compared to the study done by McShane ${ }^{[16]}$. Study conducted by Joan ${ }^{[17]}$ had maximum perinatal mortality due to RDS, whereas prematurity was the most common cause of perinatal mortality in the present study. A population-based study to investigate risk factors and pregnancy outcome of patients with placenta previa by showed placenta previa was not found as an independent risk factor for perinatal mortality. This may be attributed to the early and timely intervention in the way of elective caesarean sections $^{[18]}$.

The reported rate of foetal growth restriction/small for gestational age in the literature ranges from $3 \%$ to $5 \%$. Therefore, we have no clear evidence to implicate PP as a cause of foetal growth restriction/small for gestational age ${ }^{[18]}$. There was no maternal death due to placenta previa but there is prolonged hospital stay.

There is significant association of placenta previa with First trimester and second trimester bleeding, increased blood transfusions, need for caesarean section. Prolonged hospital stays, previous caesarean section, previous dilatation and curettage, placenta accreta, postoperative complications and NICU admission ${ }^{[19]}$.

\section{Conclusion}

The number of deliveries conducted during this study period was 7626 . In this $322(4.22 \%)$ were admitted with APH. In those 68(0.89\%) patients were of placenta previa. This study includes 60cases. Mean age was $28.96 \pm 10.42$ years. Placenta previa was more common 25-35 years age group (77\%). About $70 \%$ multiparous women had placenta previa compared to $30 \%$ primiparous women. The most common gestational age which presented with bleeding was $34-38$ week.

\section{References}

1. Faiz AS, Anath CV. Etiology and risk factors for placenta previa: an overview and meta-analysis of bservational studies. $J$ Matern Fetal Neonatal Med. 2003;13: 175190.

2. Wu S, Kocherginsky M, Hibbard J. Abnormal placentation: twenty-year analysis. Am J Obstet Gynecol. 2005;192:1458-1461.

3. Crane JM, Van den Hof MC, Dodds L, Armson BA, Liston R. Maternal complications with placenta previa. Am J Perinatol. 2000;17(2):101-5.

4. Crane JM, van den Hof MC, Dodds L, Armson BA, Liston R. Neonatal outcomes with placenta previa. Obstet Gynecol. 1999 177: 201-4.

5. Ananth CV, Smulian JC, Vintzileos AM. The effect of placenta previa on neonatal mortality: a population-based study in the United States, 1989 through 1997. Am J Obstet Gynecol. 2003;188(5):1299-304.

6. Sheiner E, Shoham-Vardi I, Hallak M, Hershkowitz R, Katz M, Mazor M. Placenta previa: obstetric risk factors and pregnancy outcome. J Matern Fetal Med. 2001;10 (6):414-9.

7. Gurol-Urganci I, Cromwell DA, Edozien LC et al. Risk of placenta previa in second birth after first birth cesarean section: a population-based study and meta-analysis. BMC Pregnancy Childbirth. 2011;11(1): 95.

8. Sharma A, Gupta I, Suri V. Tocolytic therapy in conservative management of symptomatic placenta previa. Intl J of Obstet \& Gynaecol 2004;84(2):109-13. 
9. Razia Mehboob, Nazir Ahmed. Maternal and fetal outcome in placenta previa. Pakistan J Med Res 2003;42(1):102-105.

10. Tariq khasbhoggi, Arab Board. Correlation of placenta previa with maternal and neonat outcome. Ann Saudi Med 1995;15(4).

11. Steven Clark, Koonings PP, Phelan JP. Placenta previa/ accreta and prior caesarean section. Obstet Gynaecol 1985;66(1):89-92

12. Savita Rani, Singhal, Nymphaea, et al. Maternal and perinatal outcome in APH. Intl J Obstet and Gynaecol 2008;9(2).

13. Reddy P Rani. Placenta previa- an analysis of 4 year experience. Indian $\mathbf{J}$ of Obstet Gynaecol 1999;19(3):586-8.

14. Tuzović L, Djelmis J, Ilijić M. Obstetric risk factors associated with placenta previa development: case-control study. Croat Med J. 2003;44(6):728-33.

15. Crane JM, Van den Hof MC, Dodds L, Armson BA, Liston R. Maternal complications with placenta previa. Am J Perinatol. 2000;17(2):101-5.

16. McShane PM, Heyl PS, Epstein MF. Maternal and perinatal morbidity resulting from placenta previ. J Obstet and Gynaecol 1985;65(2):176-82.

17. Joan MG, Crane Michel C, Van D, et al. Neonatal outcome in placenta previa. Am J Obstet and Gynaecol 2001;97(1):35- 8.

18. Ananth CV, Demissie K, Smulian JC, Vintzileos AM. Relationship among placenta previa, fetal growth restriction, and preterm delivery: a population-based study. Obstet Gynecol. 2001;98:299-306.

19. Farine D, Fox HE, Timor-Tritsch I. Vaginal ultrasound for ruling out placenta praevia. Case report. $\mathrm{Br} \mathrm{J}$ Obstet Gynaecol. 1989;96(1):117-9. 